REVIEW

\title{
Lipoarabinomannan, and its related glycolipids, induce divergent and opposing immune responses to Mycobacterium tuberculosis depending on structural diversity and experimental variations
}

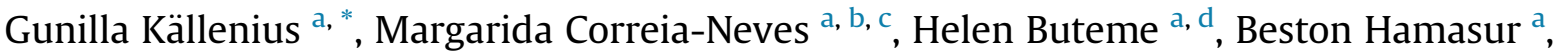 \\ Stefan B. Svenson ${ }^{a, \dagger}$ \\ ${ }^{a}$ Department of Clinical Science and Education, Karolinska Institutet, Södersjukhuset, 11883 Stockholm, Sweden \\ ${ }^{\mathrm{b}}$ Life and Health Sciences Research Institute (ICVS), School of Health Sciences, University of Minho, Braga, Portugal \\ c ICVS/3B's, PT Government Associate Laboratory, Braga/Guimarães, Portugal \\ ${ }^{\mathrm{d}}$ Department of Medical Microbiology, School of Biomedical Sciences, College of Health Sciences, Makerere University, P.O Box 7072, Kampala, Uganda
}

\section{A R T I C L E I N F O}

\section{Article history:}

Received 26 May 2015

Accepted 16 September 2015

In memoriam. Stefan Svenson, who was the architect of much of the reflections presented herein, passed away unexpectedly before this manuscript could be published. We dedicate this paper to his memory.

\section{Keywords:}

Tuberculosis

Mycobacterium

Glycolipids

Lipoarabinomannan

\begin{abstract}
S U M M A R Y
Exposure to Mycobacterium tuberculosis (Mtb) may lead to active or latent tuberculosis, or clearance of Mtb, depending essentially on the quality of the host's immune response. This response is initiated through the interaction of Mtb cell wall surface components, mostly glycolipids, with cells of the innate immune system, particularly macrophages $(\mathrm{M} \varphi s$ ) and dendritic cells (DCs). The way $\mathrm{M} \varphi s$ and DC alter their cytokine secretome, activate or inhibit different microbicidal mechanisms and present antigens and consequently trigger the T cell-mediated immune response impacts the host immune response against Mtb.

Lipoarabinomannan (LAM) is one of the major cell wall components of Mtb. Mannosyl-capped LAM (ManLAM), and its related cell wall-associated types of glycolipids/lipoglycans, namely phosphatidylinositol mannosides (PIMs) and lipomannan (LM), exhibit important and distinct immunomodulatory properties. The structure, internal heterogeneity and abundance of these molecules vary between Mtb strains exhibiting distinct degrees of virulence. Thus ManLAM, LM and PIMs may be considered crucial Mtbassociated virulence factors in the pathogenesis of tuberculosis. Of particular relevance for this review, there is controversy about the specific immunomodulatory properties of these distinct glycolipids, particularly when tested as purified molecules in vitro. In addition to the variability in the glycolipid composition conflicting reports may also result from differences in the protocols used for glycolipid isolation and for in vitro experiments including immune cell types and procedures to generate them.

Understanding the immunomodulatory properties of these cell wall glycolipids, how they differ between distinct Mtb strains, and how they influence the degree of Mtb virulence, is of utmost relevance to understand how the host mounts a protective or otherwise pathologic immune response. This is essential for the design of preventive strategies against tuberculosis. Thus, since clarifying the controversy on this matter is crucial we here review, summarize and discuss reported data from in vitro stimulation with the three major Mtb complex cell wall glycolipids (ManLAM, PIMs and LM) in an attempt to conciliate the conflicting findings.
\end{abstract}

(C) 2015 Elsevier Ltd. All rights reserved.

Contents

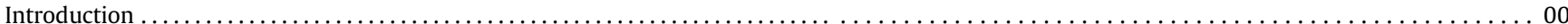

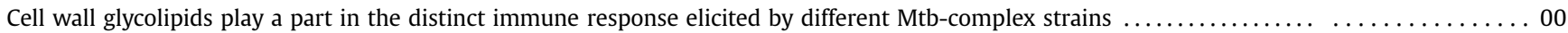

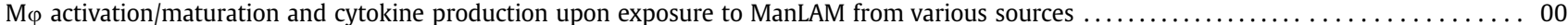

\footnotetext{
* Corresponding author. Karolinska Institutet, Department of Clinical Science and Education, Forskningscentrum plan 5, Södersjukhuset, SE-118 83 Stockholm, Sweden. Tel.: +4670 7289905.

E-mail address: gunilla.kallenius@ki.se (G. Källenius).

Deceased.
} 


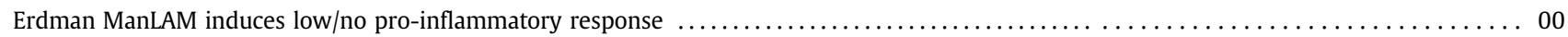

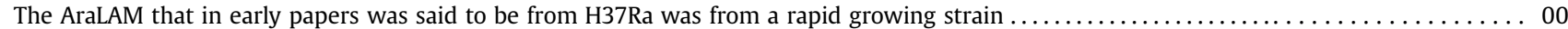

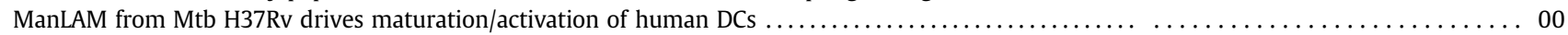

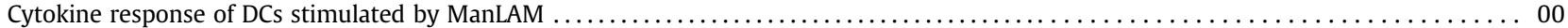

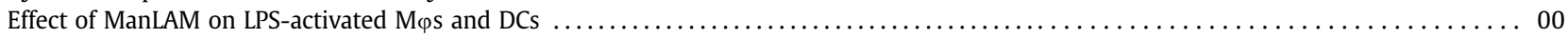

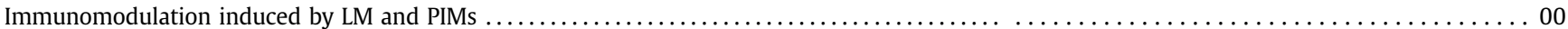

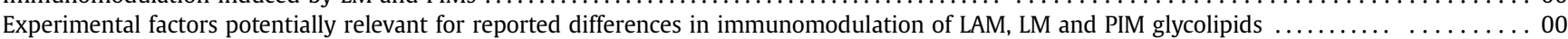

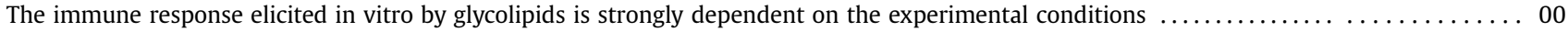

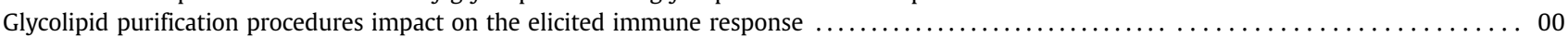

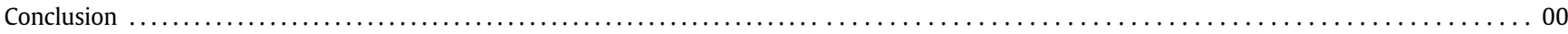

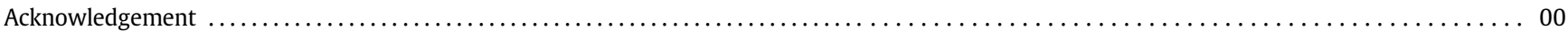

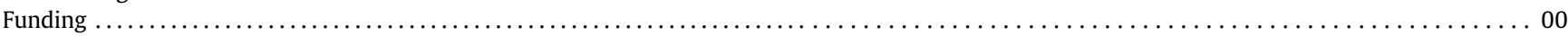

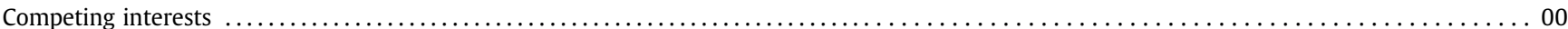

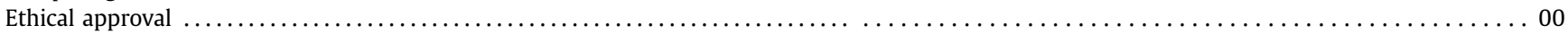

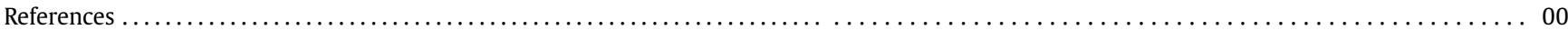

\section{Introduction}

Mycobacterium tuberculosis (Mtb) is the causative agent of tuberculosis (TB). While infection with Mtb may result in active disease, in most cases the bacteria persist in the infected host without open signs of disease [1]. The different outcomes of exposure to Mtb, active TB, latent TB or no disease, are known to depend to a large extent on the interplay between the invading Mtb and the host immune system.

Both innate and acquired branches of the immune response are essential in the battle against Mtb [2,3]. Importantly, the very first steps of the innate immune response are crucial to modulate the overall innate as well as the acquired immune response [4]. Mtb cell wall components exhibit important specific pathogen-associated molecular patterns (PAMPs); the innate immune response is initiated upon recognition of these molecules by pattern recognition receptors (PRRs), expressed mostly by macrophages (M $\varphi s)$ and dendritic cells (DCs). Several classes of PRRs have been implicated in the recognition of Mtb, including Toll-like receptors (TLRs) and Ctype lectin receptors (CLRs), such as DC-specific intercellular adhesion molecule-3 grabbing nonintegrin (DC-SIGN) [5]. There are several TLR and non-TLR PRRs involved in activation of M $\varphi s$ and DCs by Mtb. Among these, an impressive body of data shows the importance of TLR2, while reports on the involvement of other TLRs are still controversial [6-9]. Via TLRs and/or nucleotide-binding oligomerization domain receptors, intracellular signals are induced in $\mathrm{M} \varphi \mathrm{s}$ and DCs, initiating a local immune response leading to cytokine production and increased numbers of M $\varphi s$ and DCs in the infected tissue and draining lymph nodes. Following activation by cytokines and innate receptor agonists, infected $\mathrm{M} \varphi s$ elicit direct bactericidal effector functions. DCs are known to phagocytose the bacteria in infected tissues, migrate to draining lymph nodes, and initiate the adaptive immune response by priming naïve $\mathrm{T}$ and $\mathrm{B}$ lymphocytes. Here, the maturation/activation state of DCs has been shown to play an important role in their response to infection and in the subsequent acquired immune response [10].

Several cell wall associated mycobacterial glycolipids/lipoglycans ${ }^{\mathrm{e}}$ play a crucial role in the immunomodulation induced by Mtb by eliciting distinct immune responses and activating/ repressing different immune cascades [11]. In particular lipoarabinomannan (LAM) has been studied for its

\footnotetext{
e Lipoglycan or lipoglycoconjugate might be chemically more accurate terms to describe LM and LAM, however since all are based on a mannosylphosphatidylinositol anchor, the generic term glycolipid may be applicable to all three ligand classes. For the sake of simplicity we will use the term glycolipid.
}

immunomodulatory properties by numerous researchers. In addition to LAM, its precursors lipomannan (LM) [12-14] and phosphatidyl-myo-inositol mannosides (PIMs) [12-15] have been shown to have potent modulatory effects in vitro on cells of the immune system (Figure 1). LAM, LM and PIMs are all prevalent components of the mycobacterial cell wall [16]. In addition to the LAM/LM/PIM family of molecules the cell wall is composed of other lipids and glycolipids such as trehalose containing and phenolic glycolipids, as well as glyco- and lipo-proteins, which also contribute to the immune response. However these will not be the focus of this review.

In 1989 the major cell wall associated glycolipid, mannosecapped LAM (ManLAM) from Mtb was reported to stimulate the release of pro-inflammatory cytokines such as tumour necrosis factor (TNF) from human and murine $M \varphi s$ [17]. However, in subsequent publications, the reported effects of ManLAM on M $\varphi s$ and DCs were not consistent, in respect to activation and release of proinflammatory cytokines, such as interleukin (IL)-12 and IL-6 (Table 1), and expression of co-stimulatory (CD80, CD86) and antigen presenting molecules (MHC class II) (Table 2). In summary, over the last three to four decades many conflicting results on the immunomodulatory effects of ManLAM and other LAMs and their precursor molecules have accumulated, leaving the scientific community in confusion.

These and other complex and sometimes contradictory reported actions of Mtb associated cell wall glycolipids prompted us to analyse the possible reasons underlying those discrepant results. A deep analysis of the literature revealed that several factors contribute to such diverse effects and also to the lack of consistency. On one hand there are very important differences between the immunomodulatory abilities of the different glycolipids (PIM, LM, LAM and ManLAM and potentially others) present in the Mtb cell wall [18]; the analysis of the different molecules separately is essential if one aims to understand how Mtb glycolips modulate the host immune response. On the other hand, the same glycolipid may vary in composition between distinct Mtb complex strains. In addition to this inherent glycolipid diversity, differences in the protocols used to perform the experiments might also have contributed to the lack of consistency in the published results. Differences include variables associated with distinct protocols to grow the bacteria (which have a strong influence on the composition of the bacterial cell wall glycolipids); diverse strategies to isolate the distinct glycolipids (which have an effect on the composition/structure of the isolated glycolipids) compounded by the amphiphilic/amphipathic nature of LM and LAM; differences in the immune cells used (M $\varphi s$, monocytes and DC; mouse or human origin); and on the protocols used to isolate/stimulate/differentiate 


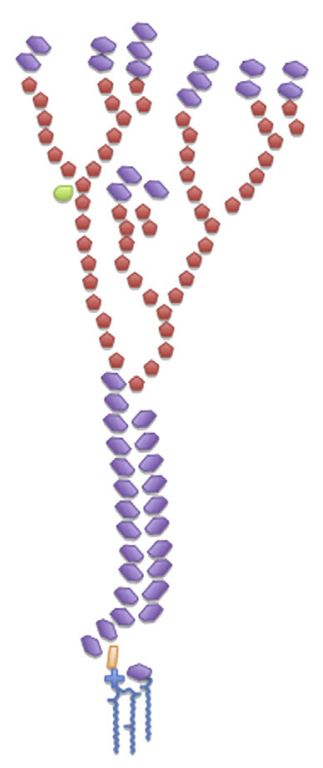

LAM
D-Arabinofuranose

D-Mannopyranose

D-Myo Inositol

Succinyl
$\{$ Palmitic Acid

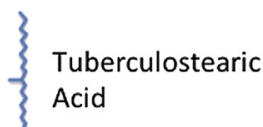

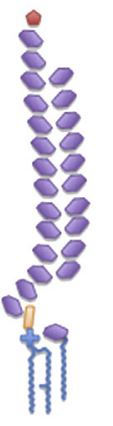

LM

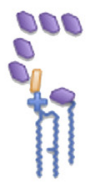

$\mathrm{PIM}_{6}$

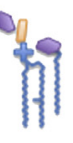

$\mathrm{PIM}_{2}$

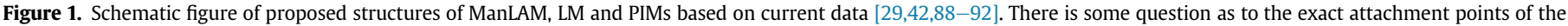
arabinan portions to the LM core in LAM, and the number of Araf residues and their arrangement can vary.

Table 1

Cytokine production by monocytes/M $\varphi$ s and DCs exposed to M. tuberculosis complex ManLAM.

\begin{tabular}{|c|c|c|c|c|c|c|c|}
\hline Publication/year & Cell type & Strains & Origin of ManLAM preparation & TNF & IL-6 & IL-12 & IL-10 \\
\hline $\begin{array}{l}\text { Monocytes/M } \varphi s \\
\text { [17] } 1989\end{array}$ & $\begin{array}{l}\text { PM mouse } \\
\text { PM mouse } \\
\text { Monocytes human } \\
\text { Monocytes human }\end{array}$ & $\begin{array}{l}\text { H37Rv } \\
\text { Mtb strain not specified } \\
\text { H37Rv } \\
\text { Mtb strain not specified }\end{array}$ & $\begin{array}{l}\text { Inhouse } \\
\text { CSU } \\
\text { Inhouse } \\
\text { CSU }\end{array}$ & $\begin{array}{l}\text { M } \\
\uparrow \\
\uparrow \\
\uparrow\end{array}$ & & & \\
\hline $\begin{array}{l}{[49] 1992} \\
{[57] 1993} \\
{[50] 1993}\end{array}$ & $\begin{array}{l}\text { PM mouse } \\
\text { BMM mouse } \\
\text { PM mouse }\end{array}$ & $\begin{array}{l}\text { Erdman } \\
\text { Erdman } \\
\text { Erdman }\end{array}$ & $\begin{array}{l}\text { CSU } \\
\text { CSU } \\
\text { CSU }\end{array}$ & $\begin{array}{l}\uparrow \\
\rightarrow \\
(\uparrow)^{*}\end{array}$ & & & \\
\hline [51] 1993 & $\begin{array}{l}\text { PM mouse } \\
\text { PM mouse } \\
\text { BMM mouse }\end{array}$ & $\begin{array}{l}\text { H37Rv } \\
\text { Erdman } \\
\text { H37Rv }\end{array}$ & $\begin{array}{l}\text { Inhouse } \\
\text { CSU } \\
\text { Inhouse }\end{array}$ & $\begin{array}{l}\uparrow \uparrow \\
(\uparrow) \\
\rightarrow\end{array}$ & & & \\
\hline [80] 1995 & BMM mouse & $\begin{array}{l}\text { H37Rv } \\
\text { Erdman }\end{array}$ & $\begin{array}{l}\text { CSU } \\
\text { CSU }\end{array}$ & $\begin{array}{l}\rightarrow \\
\rightarrow\end{array}$ & & & $\begin{array}{l}(\uparrow) \\
\rightarrow\end{array}$ \\
\hline $\begin{array}{l}{[59] 1996} \\
{[58] 1997} \\
{[72] 1998} \\
{[48] 2000}\end{array}$ & $\begin{array}{l}\text { Monocytes human } \\
\text { M } \varphi \text { murine cell line J774 } \\
\text { Human monocyte derived cell line THP-1 } \\
\text { AM human }\end{array}$ & $\begin{array}{l}\text { Erdman/H37Rv }{ }^{\dagger} \\
\text { Strain not specified } \\
\text { Erdman } \\
\text { H37Rv }\end{array}$ & $\begin{array}{l}\text { CSU } \\
\text { CSU contract N01AL-25147 } \\
\text { CSU } \\
\text { CSU }\end{array}$ & $\begin{array}{l}\uparrow \\
\rightarrow \\
\uparrow\end{array}$ & $\uparrow$ & $\begin{array}{l}\rightarrow \\
\rightarrow\end{array}$ & $(\uparrow)$ \\
\hline [7] 2004 & BMM mouse & $\begin{array}{l}\text { H37Rv } \\
\text { BCG }\end{array}$ & $\begin{array}{l}\text { CSU/CNRS } \\
\text { NRS }\end{array}$ & $\begin{array}{l}(\uparrow) \\
(\uparrow)\end{array}$ & & $\begin{array}{l}\rightarrow \\
\rightarrow\end{array}$ & \\
\hline $\begin{array}{l}{[12] 2004} \\
{[77] 2006} \\
{[93] 2010} \\
{[83] 2011}\end{array}$ & $\begin{array}{l}\text { BMM mouse } \\
\text { AM mouse } \\
\text { M } \varphi \text { human } \\
\text { PM mouse }\end{array}$ & $\begin{array}{l}\text { H37Rv } \\
\text { Mtb Ayoama B strain } \\
\text { H37Rv } \\
\text { H37Rv }\end{array}$ & $\begin{array}{l}\text { CSU } \\
\text { Nacalai Tesque Co } \\
\text { OSU } \\
\text { KI }\end{array}$ & $\begin{array}{l}\uparrow \\
\rightarrow \\
\uparrow\end{array}$ & $\rightarrow$ & $\begin{array}{l}\rightarrow \\
\rightarrow\end{array}$ & \\
\hline $\begin{array}{l}D C s \\
{[62] 1997}\end{array}$ & DC human & $\begin{array}{l}\text { BCG "parietal" } \\
\text { BCG "cellular" }\end{array}$ & $\begin{array}{l}\text { CNRS } \\
\text { CNRS }\end{array}$ & $\begin{array}{l}\uparrow \\
(\uparrow)\end{array}$ & & & \\
\hline $\begin{array}{l}\text { [64] } 2007 \\
{[65] 2011}\end{array}$ & $\begin{array}{l}\text { DC human } \\
\text { DC human }\end{array}$ & $\begin{array}{l}\text { H37Rv } \\
\text { H37Rv }\end{array}$ & $\begin{array}{l}\text { CNRS } \\
\text { CSU }\end{array}$ & $(\uparrow)$ & $\uparrow$ & $(\uparrow)$ & $\begin{array}{l}(\uparrow) \\
\text { M }\end{array}$ \\
\hline [18] 2012 & DC human & $\begin{array}{l}\text { H37Rv } \\
\text { M. bovis }\end{array}$ & $\begin{array}{l}\mathrm{KI} \\
\mathrm{KI}\end{array}$ & 个 & $\underset{\uparrow}{\uparrow}$ & $\begin{array}{l}\text { M } \\
\uparrow\end{array}$ & M \\
\hline [66] 2014 & BMDC mouse & Mtb strain not specified & Not stated & M & M & & M \\
\hline
\end{tabular}

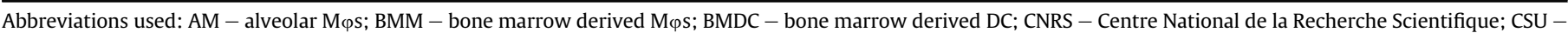
Colorado State University; KI - Karolinska Institutet; OSU - Ohio State University; PM - peritoneal M $\varphi$ s.

Symbols used: $\uparrow$ Increased production; $\downarrow$ Decreased production; $\rightarrow$ No difference.

* Brackets around arrows mean weak response.

$\dagger$ Not clear which preparation was used in which experiment. 
Table 2

Activation/maturation of M $\varphi s$ and DCs exposed to ManLAM.

\begin{tabular}{|c|c|c|c|c|c|c|}
\hline Publication/year & Cell type & Strain & Origin of ManLAM & $\begin{array}{l}\text { Activation/ } \\
\text { maturation }\end{array}$ & Activation tested & $\begin{array}{l}\text { Inhibition of IFN- } \gamma \\
\text { induced activation }\end{array}$ \\
\hline \multicolumn{7}{|l|}{$M \varphi S$} \\
\hline [52] 1988 & PM mouse & Mtb strain unknown & CSU & $\downarrow$ & $\begin{array}{l}\text { Tumoricidal and } \\
\text { Toxoplasmacidal activity }\end{array}$ & Yes \\
\hline [53] 1990 & PM mouse & Mtb strain unknown & CSU & $\downarrow$ & Tumoricidal activity & Yes \\
\hline [54] 1991 & U937 M $\varphi$-like cell line & Mtb strain unknown & CSU & $\downarrow$ & Protein kinase $\mathrm{C}$ activity & Yes \\
\hline [50] 1993 & PM mouse & Erdman & CSU & $(\uparrow)^{*}$ & Toxoplasmacidal activity & Yes \\
\hline [55] 1995 & BMM mouse & Erdman & CSU & (ヤ) & NF-kB & NT \\
\hline [7] 2004 & BMM mouse & BCG & CNRS & $(\uparrow)$ & CD40, CD86 & NT \\
\hline \multicolumn{7}{|l|}{ DCsa } \\
\hline [63] 2003 & DC human & Strain unknown & $\begin{array}{l}\text { CSU contract } \\
\text { N01AL-75320 }\end{array}$ & $\rightarrow$ & CD80, CD83, CD86 and HLA-DR & NT \\
\hline [64] 2007 & DC human & $\mathrm{H} 37 \mathrm{Rv}$ & CNRS & $\uparrow$ & CD83 and CD 86 & NT \\
\hline [65] 2011 & DC human & $\mathrm{H} 37 \mathrm{Rv}$ & CSU & $\rightarrow$ & CD83 and CD86 & NT \\
\hline [18] 2012 & DC human & $\mathrm{H} 37 \mathrm{Rv}$ & $\mathrm{KI}$ & $\uparrow$ & CD80, CD86 and MHC II & NT \\
\hline
\end{tabular}

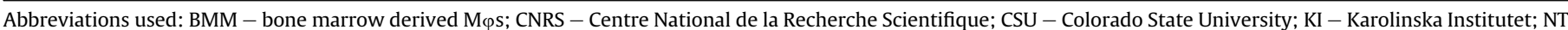
- not tested; PM - peritoneal M $\varphi$ s.

Symbols used: $\uparrow$ Increased; $\downarrow$ Decreased; $\rightarrow$ No difference.

* Brackets around arrows mean weak reactions.

these cells (which impact on the activation/maturation status of the cells, receptor (PPR) equipment and signalling pathways that are active). To all of these variables in the protocols used by distinct laboratories one needs still to consider the use of preparations of allegedly pure specific glycolipids that have been shown to be contaminated with other glycolipids or even other components [18].

In an attempt to bring some clarification to this important issue we here review the reported effects of the three major mycobacterial cell wall glycolipids, ManLAM, LM and PIMs on the maturation and cytokine profiles of murine and human M $\varphi s$ and DCs, dissecting the differences associated with the structure/composition of these molecules as well as the discrepancies that might result from experimental conditions.

Although this review focuses on the effects of glycolipids on $\mathrm{M} \varphi s$ and DCs it is of relevance to stress that these molecules also exert effects on other important cells in the immune response against Mtb. This is the case for neutrophils that in combination with alveolar $\mathrm{M} \varphi \mathrm{s}$ are recognized as the first line of defence against pulmonary TB. Several studies show how the very initial response of neutrophils, in particular the ability to trigger apoptosis, influences the overall subsequent immune response [19]. Most of these studies address how neutrophils respond to whole bacteria, which seems necessary to trigger apoptosis of neutrophils [20]. However, purified glycolipids, in particular LAM, but not PIM, have been shown to be sufficient to induce other functions, namely TRAIL release by neutrophils [21]. T cells have been mostly investigated as the main players of the acquired immune response triggered by Mtb components presented in the context of antigen presenting molecules. However, purified glycolips are also known to directly influence T cells. LAM and/or more specifically mannose capped lipoarabinomannan (ManLAM), have been shown to directly inhibit the activation/proliferation of T cells [22-24] and to specifically modulate the cytokine profile released by these cells [25].

LAMs are found in the cell wall of all mycobacterial species [26]. Generally they present a tripartite structure composed of an acylated mannosylphosphatidylinositol (MPI) anchor, attached to a poly-mannosyl backbone with arabinan branches, and different capping motifs [16,27] (Figure 1). ManLAM is most abundant in slowly growing pathogenic species of the Mtb complex, i.e. organisms causing TB, in particular Mtb and Mycobacterium bovis
[26,28] but also attenuated M. bovis, i.e. Bacillus Calmette-Guérin M. bovis (BCG). Other structural variants of LAM are PILAM (formerly called AraLAM [29]) with arabinan chains terminated with phospho-inositol motifs, such as in Mycobacterium smegmatis [30] or AraLAM devoid of any capping motifs, such as in Mycobacterium chelonae, are typical of less pathogenic mycobacteria, [29].

PIMs and LM are direct precursors of LAM; the phosphatidylinositol dimannosides $\left(\mathrm{PIM}_{2}\right)$ and hexamannosides $\left(\mathrm{PIM}_{6}\right)$ are the two most abundant classes of PIMs found in BCG and Mtb H37Rv. $\mathrm{PIM}_{2}$ gives rise to the highly mannosylated LM molecule, which is further extended by the arabinan domain to form LAM. They are non-covalently attached to the plasma membrane through their phosphatidyl-myo-inositol anchor, and extend to the exterior of the cell wall [16] although there is evidence for partial placement in the mycolic acid-rich mycobacterial outer membrane [31,32]. By contrast PIM $_{6}$ appears to be an end product [16]. LAM/LM are not single chemical entities and the basis of their structural heterogeneity may be due to variations in e.g. the number and nature of the acyl groups, length and branching of the mannan core, or arabinan component [33]. LAM, LM and PIM exhibit various acyl forms, for example the "PIM 6 family" of BCG corresponds to a mixture of 10 and 12 acylated forms [14].

\section{Cell wall glycolipids play a part in the distinct immune response elicited by different Mtb-complex strains}

It is becoming increasingly apparent that different Mtbcomplex strains induce different responses by the host's immune cells $[34,35]$. For example the magnitude and patterns of the cytokine responses in Mtb infected $M \varphi s$ is highly mycobacterial strain-dependent [7,36,37]. Human alveolar $\mathrm{M} \varphi$ s infected with the virulent laboratory strain Mtb H37Rv or $M$. bovis produce more TNF than those infected with the more attenuated Mtb H37Ra strain or with BCG [38]. In turn, human M $\varphi$ s infected with virulent clinical Mtb isolates produce more TNF than those infected with Mtb H37Rv [37]. Strains of the Mtb Beijing lineage, defined by specific RD deletions, are differentially recognized by TLRs and trigger different immune responses [36]. The mechanism responsible for these strain-related differences is most likely multi-factorial, but may in part be dependent on the different nature and relative amounts of the cell wall-associated glycolipid molecules produced by different mycobacterial strains. Small but 
important differences in glycolipid structure between individual Mtb-complex strains may account for important differences in the immune response $[14,33,39]$. It has, for example, been shown that ManLAMs from H37Rv, Mtb Erdman and BCG differ in structural aspects [28] such as mannosyloligosaccharide capping content [40], which might be important for biological function. Mtbcomplex strains containing truncated and more branched forms of mannose-capped ManLAM result in their low association with the $\mathrm{M} \varphi$ mannose receptor [39]. Thus LAM from Mtb H37Rv and BCG were reported to be heterogeneous with respect to arabinan and mannan domains and to differ in abundance of acyl-isoforms [41]. Variations in mannose-capped terminal arabinan motifs have been observed in LAMs from clinical isolates of Mtb [42], which may well be responsible for the different biological activities. Cytokine expression is influenced by the acylation state of LM ligands [43] and there is a relationship between the overall charge of the ManLAM molecule and its capacity to stimulate the production of interferon- $\gamma($ IFN- $\gamma)$ in different CD1b-restricted Tcell lines [44]. There are also differences in the ability of LAM from different Mtb strains (Erdman, H37Rv and H37Ra) to mediate adherence to $\mathrm{M} \varphi \mathrm{s}$ [45].

Culture conditions of the Mtb-complex strains have been shown to affect the composition of the isolated glycolipids [46,47]. Hence, in order to dissect the role of mycobacteria derived molecules on the innate immune responses not just the choice of mycobacterial strain for isolation of the glycolipids is of utmost importance but also the protocol used to grow the bacteria and isolate the glycolipids (discussed in more detail ahead).

\section{$M \varphi$ activation/maturation and cytokine production upon exposure to ManLAM from various sources}

ManLAMs purified from Mtb complex were, in early studies in the late 1980 s early 1990 s, found to stimulate the production of pro-inflammatory cytokines, in particular TNF, by both human $[17,48]$ and mouse $[17,49-51] \mathrm{M} \varphi$ s (Table 1). However, the reported magnitude of the TNF secretion varied greatly between studies. ManLAM has also been reported to affect other $\mathrm{M} \varphi$ functions, such as inhibition of various IFN- $\gamma$ mediated microbicidal and tumoricidal activities [52-54], but it has also been reported that ManLAM can trigger the microbicidal activity of IFN- $\gamma$-primed $\mathrm{M} \varphi \mathrm{s}$ [50].

In the report by Moreno et al. [17] in 1989 treatment of the ManLAM with alkali greatly reduced the TNF-secreting activity, suggesting that $\mathrm{O}$-acyl groups were involved. A few years later ManLAM derived from the "virulent" laboratory Mtb strain Erdman was reported to be a weak stimulator of a pro-inflammatory response in respect to TNF production [49] and stimulation of NF$\mathrm{kB}$ [55] in mouse M $\varphi s$ compared to LAM isolated from the so called "avirulent" H37Ra laboratory strain. Some of the discordant information about the effect of ManLAM on the induction of a proinflammatory response by $\mathrm{M} \varphi \mathrm{s}$ apparently stem from these early papers.

\section{Erdman ManLAM induces low/no pro-inflammatory response}

ManLAM prepared from the Mtb Erdman strain [56] was used in many of the early studies analyzing $M \varphi$ activation (Table 2) and cytokine production (Table 1). Erdman ManLAM preparations were repeatedly reported to either fail to induce the production of TNF in mouse $[49,50,57] \mathrm{M} \varphi \mathrm{s}$, or to produce very low amounts of TNF (Table 1), not only compared to LAM (AraLAM, see ahead) prepared from the so called "avirulent" H37Ra laboratory strain $[49-51,57]$ (see ahead) but also compared to ManLAM from H37Rv [51]. When ManLAM preparations from the strains H37Rv and Erdman were examined side by side [51], H37Rv ManLAM was found to induce higher amounts of TNF compared to that from Erdman [51] in murine peritoneal $\mathrm{M} \varphi s$. ManLAM from Erdman also failed to induce IL-12p40 in mouse $\mathrm{M} \varphi \mathrm{s}$ [58]. Reports suggest that IFN $-\gamma$ activation is needed to stimulate TNF production through stimulation of peritoneal $\mathrm{M} \varphi \mathrm{S}$ with Erdman ManLAM [50], while in other studies bone marrow derived cells were unresponsive to Erdman ManLAM despite IFN$\gamma$ activation [57].

\section{The AraLAM that in early papers was said to be from H37Ra was from a rapid growing strain}

Part of the discordant results from the early in vitro experiments $[13,49,50]$ stems from the fact that the AraLAM (without mannose cap, and a potent inducer of TNF) that in these early papers was said to stem from the "avirulent" attenuated H37Ra strain in fact came from a rapidly growing mycobacteria species, presumably M. smegmatis [28,29], in which LAM is not mannose-capped (while LAMs from both H37Rv and H37Ra are mannose capped) [29]. In general, LAM lacking mannose capping (AraLAM/PILAM) stimulates higher TNF production than ManLAM from Mtb-complex strains [59], indicating that the amount of mannose capping may be responsible for the pro-inflammatory capacity of a particular strain. Indeed the Erdman Mtb strain is reported to be significantly more mannose-capped, compared to H37Rv [40] and H37Ra [29,40], which may be part of the explanation for its low/absent proinflammatory activity. However, although the loss of LAM mannose caps in a mutant of BCG induced a somewhat higher production of TNF in $\mathrm{M} \varphi \mathrm{s}$, as compared to the wild type strain, it did not affect the production of TNF in DCs [60]. Neither did the lack of the mannose cap in a Mtb mutant affect its virulence in mice [60] an observation that deserves attention in the future.

\section{ManLAM from Mtb H37Rv drives maturation/activation of human $D C S$}

The interaction of ManLAM with DCs, in particular with human DCs, is less well studied than the interaction with M $\varphi s$ [61-63]. It was demonstrated that a highly purified H37Rv ManLAM was a potent activator of human DCs showing several similarities with LPS in respect to DC cytokine production and cell maturation profile [18] (Table 2). These observations are in agreement with the findings by Dulphy et al. [64] where DCs were activated with ManLAM from H37Rv, displaying a dose-dependent maturation phenotype, in terms of CD83 and CD86 expression but in contrast to the findings by Geijtenbeek et al. [63] and Wu et al. [65] where ManLAM did not induce DC maturation. The reason for this discrepancy is not clear but it could be hypothesized that also here strain-associated differences in the relative abundance of molecular forms of ManLAM or/and degree of purity of the preparation used could contribute to the observed divergent effects on DC maturation.

\section{Cytokine response of DCs stimulated by ManLAM}

ManLAM from H37Rv was shown to induce a strong proinflammatory cytokine response in human DCs, manifested by TNF, IL-6, and IL-12 release [18] (Table 1). Similar results were reported in a recent study using mouse cells, where ManLAM activated bone-marrow-derived DC were shown to produce pro- and anti-inflammatory cytokines via a C-type lectin receptor, Dectin-2 [66]. Thus ManLAM induces the production of TNF and IL-6 as well as the anti-inflammatory cytokine IL-10. In a study by Dulphy et al. [64], ManLAM-activated DCs produced the pro-inflammatory cytokines IL- 6 and IL- 8 but at a lower amount compared with cells 
stimulated by LPS, as well as low amounts of IL-10 and the functional IL-12p70 heterodimer.

In an earlier study by Nigou et al. different types of ManLAM obtained from BCG were reported to have different stimulatory capacity [62]. While the cell wall-associated preparation, "parietal" ManLAM, was shown to induce TNF and IL-8 production, the cell membrane-associated "cellular" ManLAM preparation did not induce a clear production of TNF or IL-8 [62]. The "parietal" type was reported to be uniquely O-acylated and Man-capped to a larger extent than the "cellular" type [62].

Considering its TNF stimulatory effect, the H37Rv ManLAM preparation investigated by Mazurek et al. [18] behaved as the "parietal" ManLAM used by Nigou et al. [62]; however, one should keep in mind that more than $90 \%$ of ManLAM preparations from BCG consists of "cellular" ManLAM [62]. A potential reason for the discrepant results in terms of pro-inflammatory responses by ManLAM may be differences in the strains from which the ManLAM was isolated. Thus ManLAM derived from M. bovis was shown to induce pro-inflammatory cytokines in DCs at a much lower level than ManLAM from H37Rv [18]. The ManLAM used by Nigou et al. was from BCG [62], while the ManLAMs used by Mazurek et al. [18] and Dulphy et al. [64] were from H37Rv (Table 1). Yet another reason could be differences in the type of DCs used and protocols to prepare these cells.

ManLAM has been reported to be unable to trigger IL-10 release from human blood monocytes [59]. However, ManLAM preparations from H37Rv induced IL-10 from human DCs in the study by Mazurek et al. [18] as well as in a study using mouse DC [66]. This was hardly surprising given that IL-10 is secreted in response to TLR ligation as well as to high levels of TNF and IL-6 [67] in a negative feedback manner.

\section{Effect of ManLAM on LPS-activated M $\varphi$ S and DCs}

The pro-inflammatory molecule LPS [68] is known to drive maturation of $\mathrm{M} \varphi \mathrm{s}$ [69] and DCs, and triggers production of proinflammatory cytokines [70] such as TNF, IL-6, and IL-12. For this reason the interaction between ManLAM and LPS has been studied, and also here the activity of various ManLAM preparations varies in different experimental setups (Table 3 ). In early studies Erdman ManLAM was found to block subsequent LPS-induced $\mathrm{M} \varphi$ activation [50]. On the other hand a more recent study showed that H37Rv ManLAM potentiated the LPS-induced expression of CD80, but not the expression of CD86, or MHC II, and stimulated a moderate but significant increase of cytokine production (TNF, IL-6, and IL-12) in human DCs over that induced by LPS alone [18]. Similar observations for IL-12p35, IL-12p40, IL-6 and IL-10 were made by Gringhuis et al. [71] who found that the production of cytokines was increased when cells were treated with LPS together with ManLAM as compared to cells exposed to LPS alone [71]. The findings that H37Rv ManLAM provides additional stimuli to the LPS-induced cytokine secretion, resulting in the augmented cytokine output, suggests that different PRRs on human DCs may be involved in the ManLAM-as compared to LPS-driven cytokine responses.

In contrast with these results a paper by Nigou et al. reported that the "cellular" ManLAM preparation from BCG inhibited IL-12 secretion by human DCs when stimulated with LPS [61]. A similar negative effect was reported by Knutson et al. [72] making use of a monocyte cell line. Also reporting a negative effect the study by Geijtenbeek et al. [63] showed that Mtb ManLAM inhibited LPSinduced DC maturation.

\section{Immunomodulation induced by LM and PIMs}

LMs from different mycobacterial species have been reported to exhibit contradictory activities, both pro-inflammatory and antiinflammatory responses through TLR2-dependent and -independent pathways $[7,43,73]$ (Table 4). LM, including LM purified from H37Rv, has been shown to induce IL-12 production in a TLR-2 dependent manner [12] and also inhibit IL-12 production in a TLR-independent manner [7]. LM (from BCG and Mtb H37Rv) has been reported to be a strong inducer of TNF through a TLR2 dependent pathway [74], but LM from H37Rv has been also reported to block TNF biosynthesis [75]. LM purified from M. chelonae and Mycobacterium kansasii has been described to induce TNF and IL-8 secretion through a CD14-TLR2-dependent mechanism [73]. The LM activity appears to depend on the acylation degree [14], on the length of the mannan chain building the mannopyranosyl backbone of LM [74] and to be determined by binding to TLR2 [74].

$\mathrm{PIM}_{2}$ and $\mathrm{PIM}_{6}$ are the two most abundant classes of PIMs found in Mtb and BCG [76]. In earlier studies non-fractionated PIMs from H37Ra [15,77] and PIM 6 from BCG [14] were reported to stimulate the production of TNF through TLR2 signalling in $M \varphi s[14,15]$ (Table 5). According to the authors this effect depended on the presence of the lipid component of the molecule as de-acylation of $\mathrm{PIM}_{6}$ abrogated the TNF production [14]. By contrast, in a recent report, $\mathrm{PIM}_{2}$ and $\mathrm{PIM}_{6}$ from BCG were reported to present antiinflammatory activities, inhibiting LPS-induced TNF, IL-12, IL-6, but also inflammatory activities by inhibiting IL-10 production in mouse M $\varphi s$ through a TLR2-independent mechanism [76]. These

Table 3

Effect of ManLAM on LPS-induced cytokine production and maturation by M $\varphi s$ and DCs.

\begin{tabular}{|c|c|c|c|c|c|c|c|c|}
\hline \multirow[t]{2}{*}{ Publication/year } & \multirow[t]{2}{*}{ Cell type } & \multirow[t]{2}{*}{ Strain } & \multirow[t]{2}{*}{ Origin of ManLAM } & \multicolumn{4}{|c|}{ Cytokine production } & \multirow[t]{2}{*}{ Maturation (markers) } \\
\hline & & & & TNF & IL-6 & IL-12 & IL-10 & \\
\hline [59] 1996 & Monocytes human & Erdman/H37Rv & CSU & $(\uparrow)^{*}$ & & & & \\
\hline [72] 1998 & $\begin{array}{l}\text { Human monocyte } \\
\text { derived cell line THP-1 }\end{array}$ & Erdman & CSU contract NO1 AI-25147 & $\downarrow$ & & $\downarrow$ & & $\downarrow(\mathrm{MHX})$ \\
\hline [61] 2001 & DC human & $\mathrm{BCG}^{\dagger}$ & CNRS & & & $\downarrow$ & & \\
\hline [63] 2003 & DC human & Mtb strain unknown & CSU contract NO1 AI-75320 & & & & $\uparrow$ & $\downarrow(C D 80$, CD83 and CD86) \\
\hline [7] 2004 & BMM mouse & BCG & CNRS & $\downarrow$ & & $\downarrow$ & & \\
\hline [94] 2005 & Raw cell line & H37Rv & CSU & & & $\downarrow$ & & \\
\hline [71] 2009 & DC human & Mtb strain unknown & CSU & & $\uparrow$ & $\uparrow$ & $\uparrow$ & \\
\hline [18] 2012 & DC human & $\mathrm{H} 37 \mathrm{Rv}$ & $\mathrm{KI}$ & $\uparrow$ & $\uparrow$ & $\uparrow$ & $\uparrow$ & $\begin{array}{l}\uparrow(C D 80) \\
\rightarrow(C D 86 \text { and } M H C \text { II })\end{array}$ \\
\hline [95] 2013 & DC human & BCG & Not stated & $\rightarrow$ & $\downarrow$ & & $\uparrow$ & \\
\hline
\end{tabular}

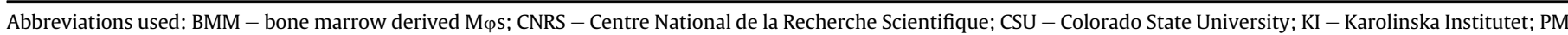
- peritoneal $\mathrm{M} \varphi \mathrm{s}$.

Symbols used: $\uparrow$ Increased production; $\downarrow$ Decreased production; $\rightarrow$ No difference.

* Brackets around arrows mean weak reactions.

† "Cellular" ManLAM, not parietal. 
Table 4

Activation/maturation of M $\varphi$ s exposed to LM.

\begin{tabular}{|c|c|c|c|c|c|c|c|c|}
\hline Publication/year & Cell type & Strain & Origin of LM & TNF & IL-12 & CD40, CD80 & Down-regulation & Ligand \\
\hline [7] 2004 & BMM mouse & $\begin{array}{l}\text { BCG } \\
\text { H37Rv }\end{array}$ & $\begin{array}{l}\text { Inhouse } \\
\text { CSU/inhouse }\end{array}$ & $\begin{array}{l}\uparrow \\
\uparrow\end{array}$ & $\begin{array}{l}\uparrow \\
\uparrow\end{array}$ & $\uparrow$ & & \\
\hline [12] 2004 & BMM mouse & H37Rv & CSU & & $M$ & & & TLR2 \\
\hline [96] 2006 & $\begin{array}{l}\text { BMM mouse and Human } \\
\text { monocyte derived cell line THP-1 }\end{array}$ & BCG & CNRS & $\uparrow \star$ & & & & TLR2 \\
\hline [43] 2007 & BMM mouse & BCG & CNRS & & $\star \star$ & & $\star \star$ & $\star \star$ \\
\hline [74] 2008 & $\begin{array}{l}\text { Human monocyte derived } \\
\text { cell line THP-1 }\end{array}$ & H37Rv & CNRS & $\underset{\star \star \star}{M}$ & & & & TLR2 \\
\hline [75] 2011 & MDM human & H37Rv & Inhouse & $\downarrow$ & & & Yes & \\
\hline
\end{tabular}

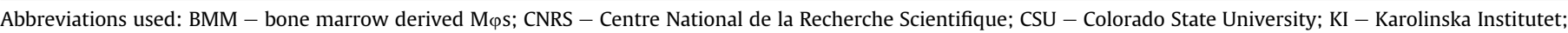
$\mathrm{MDM}$ - monocyte derived M $\varphi s ; \mathrm{PM}$ - peritoneal M $\varphi s$.

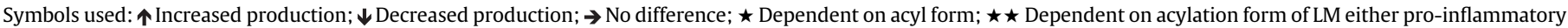
or negative inflammatory activity through varying ligands; $\star \star \star$ Activity dependent on mannan chain length of backbone.

Table 5

Activation/maturation and cytokine production of M $\varphi s$ and DCs exposed to PIM.

\begin{tabular}{|c|c|c|c|c|c|c|c|}
\hline Publication/year & Cell type & Strain & Origin of PIM & Type of PIM & Cytokines & Activation/maturation & Inhibits LPS activation \\
\hline [49] 1991 & PM mouse & H37Ra & CSU & & $\operatorname{TNF}(\boldsymbol{\uparrow})^{*}$ & & \\
\hline [15] 2001 & Raw $\mathrm{M} \varphi$ mouse cell line & H37Ra & CSU & & $\operatorname{TNF}(\boldsymbol{\uparrow})$ & TLR2 agonist & \\
\hline [14] 2003 & PM mouse & BCG & CNRS & $\mathrm{PIM}_{2}$ and $\mathrm{PIM}_{6}$ & $\operatorname{TNF}(\boldsymbol{\uparrow})$ & TLR2 agonist & \\
\hline [12] 2004 & BMM mouse & H37Rv & CSU & $\mathrm{PIM}_{2}$ & IL-12 $\rightarrow$ & & \\
\hline \multirow[t]{2}{*}{ [77] 2006} & PM mouse & \multirow[t]{2}{*}{ H37Rv } & \multirow[t]{2}{*}{ Inhouse } & & \multirow{2}{*}{\multicolumn{2}{|c|}{$\begin{array}{l}\text { TNF (覓) } \\
\operatorname{TNF}(\boldsymbol{\uparrow})\end{array}$}} & \\
\hline & AM mouse & & & & & & \\
\hline [76] 2009 & BMM mouse & BCG & CNRS & $\mathrm{PIM}_{6}$ & ND & $\begin{array}{l}\text { LPS inhibition } \\
\text { TLR2 independent }\end{array}$ & TNF, IL-6, IL-12p40 w \\
\hline [76] 2009 & BMM mouse & NA & Synthetic & $\mathrm{PIM}_{2}$ mimetic & ND & $\begin{array}{l}\text { LPS inhibition } \\
\text { TLR2 independent }\end{array}$ & TNF, IL-6, IL-12p40 ฟ \\
\hline \multirow[t]{2}{*}{ [18] 2012} & \multirow[t]{2}{*}{ DC human } & H37Rv & KI & & \multirow[t]{2}{*}{ TNF, IL-6, IL-12 $\rightarrow$} & \multirow[t]{2}{*}{ CD80, CD86 and MHC II $\rightarrow$} & \multirow[t]{2}{*}{ TNF, IL-6, IL-12p40 w } \\
\hline & & M. bovis & KI & & & & \\
\hline
\end{tabular}

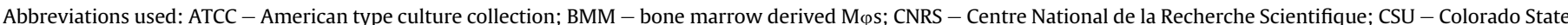
University; KI - Karolinska Institutet; PM - Pulmonary M $\varphi s$.

Symbols used: $\uparrow$ Increased production; $\rightarrow$ No difference.

* Brackets around arrows mean weak reactions.

effects were reported to depend on the acylation degree; di-and triacylated PIMs were strongly inhibitory, while tetra-acylated were less inhibitory, and mono-acylated PIMs were non inhibitory [76].

The observations by Doz et al. of a prominent anti-inflammatory action of PIMs on murine $\mathrm{M} \varphi s$ [76] were corroborated and extended by Mazurek et al. using human DCs [18]. In these studies $\mathrm{PIM}_{2}$ and total PIM, isolated both from Mtb H37Rv and BCG, were reported to be potent inhibitors of the LPS-driven activation of human DCs [18]. PIMs reduced LPS-driven up-regulation of MHC II but did not modulate LPS-induced expression of the co-stimulatory molecules CD80 and CD86 [18]. In addition, PIMs also abrogated ManLAM-elicited augmentation of pro-inflammatory cytokine production (TNF, IL-6 as well as IL-12p40) in LPS-treated DCs [18]. Unlike ManLAM, PIMs alone did not affect surface expression of DC maturation markers (Table 5). Thus, the inhibition of LPS-induced cytokine production does not seem to be caused by delayed maturation/activation of DCs but rather by a down-regulation of either transcription and/or secretion of those cytokines. PIMs from $M$. bovis showed inhibitory activity similar to that of PIMs from Mtb H37Rv [18]. This is consistent with the fact that the two differently acylated isoforms of $\mathrm{PIM}_{2}$ and $\mathrm{PIM}_{6}$ are simultaneously present in both Mtb H37Rv and BCG [78]. More recently synthetic PIM $\mathrm{M}_{1}$ and $\mathrm{PIM}_{2}$ analogues were also shown to inhibit TNF and IL-12p40 expression induced by TLR2 or TLR4 pathways in murine M $\varphi s$ $[76,79]$. PIM 1 and PIM $_{2}$ inhibited LPS-induced TNF release by a CD14-dependent pathway, while IL-12p40 inhibition was CD14 independent.
In conclusion there is clear evidence that certain PIMs from Mtb H37Rv, M. bovis and BCG are potent anti-inflammatory agents that inhibit the pro-inflammatory activity of both LPS and ManLAM.

\section{Experimental factors potentially relevant for reported differences in immunomodulation of LAM, LM and PIM glycolipids}

The immune response elicited in vitro by glycolipids is strongly dependent on the experimental conditions

The type and activation state as well as the origin of cells (human/animal) chosen for in vitro stimulation experiments may profoundly affect the final outcome. Bradbury and Moreno [51] examined the action of ManLAM on murine peritoneal and bone marrow derived $\mathrm{M} \varphi s$ and found that only the former produced TNF in response to H37Rv ManLAM. In accordance, several preparations of ManLAM from Mtb H37Rv [7,80] and Erdman [57,80] failed to induce TNF production in murine bone marrow derived $\mathrm{M} \varphi \mathrm{s}$. Presumably mouse bone marrow derived $\mathrm{M} \varphi \mathrm{s}$ are less "mature" or more naive than those derived from intraperitoneal sources [81]. Various methods of in vitro $\mathrm{M} \varphi$ maturation confer variable capacity for inflammatory responses [82], and it could thus be speculated that $\mathrm{M}-\mathrm{CSF}$, used to propagate $\mathrm{M} \varphi \mathrm{s}$ from bone marrow, being a potent regulator of $\mathrm{M} \varphi$ receptors expression, affects the expression of ManLAM-recognizing receptors [83]. 
Molecules of the LAM/LM/PIM family have been reported to bind to and signal through various PPRs on host cells. Some of these molecules bind to TLR2 and/or other TLRs [6-8], while others, such as ManLAM, are thought to bind DC-specific C-type lectin DC-SIGN/ CD209 and mannose receptors and to deliver negative signals that interfere with TLR-mediated signalling [61]. Mycobacterial lipoglycans of the LAM/PIM family show a varying degree of TLR2dependent pro-inflammatory activities [74]. Thus, since PPR expression is strongly influenced by the cells used and the protocol applied to prepare them, one need to pay special attention to this information when analyzing the data generated.

Other experimental factors that may influence results are e.g. time of exposure and amounts of ManLAM used in the treatment of cells as well as its presentation. Thus for example augmentation of LPS-induced TNF production was found after short stimulation (1-4 h) of M $\varphi s$ with ManLAM [59,83], while it was not observed after prolonged exposure [83]. The stimulation of Dectin-2 receptor with ManLAM induced the production of both pro- and anti-inflammatory cytokines according to its presentation (soluble/plate coated) [66].

\section{Glycolipid purification procedures impact on the elicited immune response}

Several procedures have been described by different laboratories for the purification of LAM and other mycobacterial glycolipids $[74,84]$. Generally, these procedures rely on the initial extraction from dried bacterial cells or cell walls with a lipophilic organic solvent/water system, followed by hydrophobic interaction and size exclusion chromatography in the presence of a detergent. These purification methods may result in complex glycolipid fractions of varying compositions that are not limited to mannosylterminated glycolipid species alone. In addition, in many instances the purification procedure used, and most importantly the methods used to control the purity of the preparations are not described.

ManLAM preparations from Colorado State University (CSU) have over the years been used by many investigators, and are regarded as the gold standard. During recent years they have been produced under NIH contracts, as TB Vaccine Testing and Research Materials (TBVTRM). We recently found that some TBVTRM ManLAM preparations were contaminated with other potent immunomodulary molecules that might affect the biological activity of the preparations [18]. Of two TBVTRM ManLAM lots investigated both were shown to contain PIMs and also some unidentified high molecular weight materials in addition to ManLAM. One TBVTRM lot tested showed a very high content of glucose suggesting contamination with mycobacterial glucans. One fraction was most likely arabinomannan (AM), devoid of most or completely lacking the lipid (acyl) part of ManLAM [18] (Figure 1).

Altogether the findings of contaminating materials (glucans, PIMs) and potential lack of acylation of the ManLAM in the TBVTRM ManLAM preparation described previously [18] may explain some observations where TBVTRM ManLAM preparations have been used. Thus mycobacterial glucans have been reported to suppress IL-12 production in monocyte-derived DCs [85]. The degree of acylation of mycobacterial glycolipids is important for e.g. the regulation of pro-inflammatory cytokines $[14,43,86]$ so nonacylated or only partially acylated LAM in a ManLAM preparation might exert a competitory/inhibitory effect on the ManLAM. High levels of contaminating anti-inflammatory PIMs may also compete with or inhibit the effects induced by a particular ManLAM lot (see ahead).

It must also be remembered that all of these studies have in common the introduction of exogenous isolated ManLAM or other glycolipid ligands into essentially hydrophilic in vitro assays; yet, these are all highly amphipathic with varying degrees of aqueous compatibility, an important consideration in explaining contradictory outcomes. Now, with the availability of mutants of Mtb devoid of key structural/immunogenic aspects of LAM and LM, a whole bacterium approach can be applied to these questions [87].

\section{Conclusion}

In conclusion, we here review the profound and divergent effects of the major family of lipoglycans ManLAM, LM and PIMs, on $\mathrm{M} \varphi s$ and DCs with regard to cell maturation and cytokine responses, and try to conciliate conflicting reports about the specific properties of these glycolipids. We summarize data showing that the described discrepancies are associated on one hand with differences in glycolipids themselves and/or their preparation, and on the other hand with differences in the cells used in the experiments.

With respect to the glycolipids one should keep in mind the variability in their composition, discrete differences in structure, the use of glycolipids from different bacterial strains and also differences in the protocols used for glycolipid isolation. Part of the discordant views of LAM stem from early experiments where AraLAM (without mannose cap, and a potent inducer of TNF) that in early papers $[11,36,37]$ was said to stem from the "avirulent" attenuated H37Ra strain in fact came from a rapidly growing strain. Furthermore in some instances the contradictions may have been caused by the use of LAM preparations that were not sufficiently pure, containing, in addition to LAM, other related biologically active molecules.

ManLAM presents varying degrees of pro-inflammatory capacity, depending on the strain it comes from. ManLAM from the laboratory strain Mtb Erdman shows extremely low or no pro- and anti-inflammatory activity, compared to ManLAM from Mtb H37Rv. Some of the low pro-inflammatory activities reported for certain ManLAM preparations may depend on contamination with e.g. PIMs as a result of the difficulty in separating ManLAM and PIM during the isolation process of ManLAM.

A point seldom recognized is that LAM of whatever flavour, and LM, as we know them chemically, consist of a heterogeneous population and the structures presented (e.g. Figure 1) are average representations. Hence, in order to dissect the role of mycobacteria derived molecules in innate immune responses the choice of mycobacterial strain for isolation of the glycolipids is of utmost importance.

It is conceivable that different LAM/PIM ratios in the cell wall of different bacterial strains, and during distinct stages of Mtb infection [47], may be a crucial factor in determining the differential Mtb stimulation or inhibition of the immune system and thereby be decisive for the emergence and outcome of the disease $[7,16,18]$.

Some of the discrepant results may be explained by differences in the cells that were used, such as differences in maturation (resting or already activated) or receptor equipment (TLR, DC-SIGN, mannose receptor etc). One early publication by Bradbury and Moreno [51] clearly illustrates this, where they examined the action of ManLAM on murine peritoneal and bone marrow derived $M \varphi s$ and found that only the former produced TNF in response to H37Rv ManLAM.

Thus, unless head to head experiments are performed, using the same cells, definitive conclusions are difficult to achieve regarding quantitative and even qualitative differences in maturation and cytokine expression.

It will not be possible or even desirable to achieve full consistency in experiments utilizing lipoglycans and immune cells within 
this large scientific field. However we think that it is important to be aware of the discrepancies described here to be able to critically compare data from distinct sources, to evaluate the relevance of individual experiments and to design properly future research on LAM and its related molecules. To be able to do so it is important that the glycolipids and cells used in the studies are well characterized and that the methods and protocols for preparation of glycolipids and cells are carefully documented.

\section{Acknowledgement}

We thank Jerome Nigou for critically reading the manuscript and Bruno Cerqueira-Rodrigues for drawing the figure.

\section{Funding}

None.

\section{Competing interests}

None declared.

\section{Ethical approval}

Not required.

\section{References}

[1] Dutta NK, Karakousis PC. Latent tuberculosis infection: myths, models, and molecular mechanisms. Microbiol Mol Biol Rev 2014;78:343-71.

[2] O'Garra A, Redford PS, McNab FW, Bloom CI, Wilkinson RJ, Berry MP. The immune response in tuberculosis. Annu Rev Immunol 2013;31:475-527.

[3] Cooper AM, Mayer-Barber KD, Sher A. Role of innate cytokines in mycobacterial infection. Mucosal Immunol 2011:4:252-60.

[4] Saraav I, Singh S, Sharma S. Outcome of Mycobacterium tuberculosis and Tolllike receptor interaction: immune response or immune evasion? Immuno Cell Biol 2014;92:741-6.

[5] Kleinnijenhuis J, Oosting M, Joosten LA, Netea MG, Van Crevel R. Innate immune recognition of Mycobacterium tuberculosis. Clin Dev Immunol 2011;2011:405310.

[6] Means TK, Wang S, Lien E, Yoshimura A, Golenbock DT, Fenton MJ. Human toll-like receptors mediate cellular activation by Mycobacterium tuberculosis. J Immunol 1999;163:3920-7.

[7] Quesniaux VJ, Nicolle DM, Torres D, Kremer L, Guérardel Y, Nigou J, Puzo G, Erard F, Ryffel B.. Toll-like receptor 2 (TLR2)-dependent-positive and TLR2independent-negative regulation of proinflammatory cytokines by mycobacterial lipomannans. J Immunol 2004;172:4425-34.

[8] Mortaz E, Adcock IM, Tabarsi P, Masjedi MR, Mansouri D, Velayati AA, Casanova JL, Barnes PJ. Interaction of pattern recognition receptors with Mycobacterium tuberculosis. J Clin Immunol 2014 Oct 14 [Epub ahead of print] PMID: 25312698.

[9] Reiling N, Hölscher C, Fehrenbach A, Kröger S, Kirschning CJ, Goyert S, Ehlers S Cutting edge: toll-like receptor (TLR)2- and TLR4-mediated pathogen recognition in resistance to airborne infection with Mycobacterium tuberculosis J Immunol 2002;169:3480-4.

[10] Kim KD, Lee HG, Kim JK, Park SN, Choe IS, Choe YK, Kim SJ, Lee E, Lim JS Enhanced antigen-presenting activity and tumour necrosis factor-alphaindependent activation of dendritic cells following treatment with Mycobacterium bovis bacillus Calmette-Guerin. Immunology 1999;97:626-33.

[11] Karakousis PC, Bishai WR, Dorman SE. Mycobacterium tuberculosis cell enve lope lipids and the host immune response. Cell Microbiol 2004;6:105-16.

[12] Dao DN, Kremer L, Guérardel Y, Molano A, Jacobs Jr WR, Porcelli SA, Briken V. Mycobacterium tuberculosis lipomannan induces apoptosis and interleukin-12 production in macrophages. Infect Immun 2004;72:2067-74.

[13] Barnes PF, Chatterjee D, Abrams JS, Lu S, Wang E, Yamamura M, Brennan PJ, Modlin RL. Cytokine production induced by Mycobacterium tuberculosis lipoarabinomannan. Relationship to chemical structure. J Immunol 1992;149: $541-7$.

[14] Gilleron M, Quesniaux VF, Puzo G. Acylation state of the phosphatidylinosito hexamannosides from Mycobacterium bovis bacillus Calmette Guerin and Mycobacterium tuberculosis H37Rv and its implication in Toll-like receptor response. J Biol Chem 2003;278:29880-9.

[15] Jones BW, Means TK, Heldwein KA, Keen MA, Hill PJ, Belisle JT, Fenton MJ. Different Toll-like receptor agonists induce distinct macrophage responses. J Leukoc Biol 2001;69:1036-44.
[16] Briken V, Porcelli SA, Besra GS, Kremer L. Mycobacterial lipoarabinomannan and related lipoglycans: from biogenesis to modulation of the immune response. Mol Microbiol 2004;53:391-403.

[17] Moreno C, Taverne J, Mehlert A, Bate CA, Brealey RJ, Meager A, Rook GA, Playfair JH. Lipoarabinomannan from Mycobacterium tuberculosis induces the production of tumour necrosis factor from human and murine macrophages. Clin Exp Immunol 1989;76:240-5.

[18] Mazurek J, Ignatowicz L, Kallenius G, Svenson SB, Pawlowski A, Hamasur B. Divergent effects of mycobacterial cell wall glycolipids on maturation and function of human monocyte-derived dendritic cells. PLoS ONE 2012;7: e42515.

[19] Aleman M. Neutrophil apoptosis in the context of tuberculosis infection. Tuberculosis (Edinb) 2015;95:359-63.

[20] Aleman M, Schierloh P, de la Barrera SS, Musella RM, Saab MA, Baldini M, Abbate E, Sasiain MC. Mycobacterium tuberculosis triggers apoptosis in peripheral neutrophils involving toll-like receptor 2 and p38 mitogen protein kinase in tuberculosis patients. Infect Immun 2004;72:5150-8.

[21] Simons MP, Moore JM, Kemp TJ, Griffith TS. Identification of the mycobacterial subcomponents involved in the release of tumor necrosis factor-related apoptosis-inducing ligand from human neutrophils. Infect Immun 2007;75: 1265-71.

[22] Mahon RN, Rojas RE, Fulton SA, Franko JL, Harding CV, Boom WH. Mycobacterium tuberculosis cell wall glycolipids directly inhibit CD4+ T-cell activation by interfering with proximal T-cell-receptor signaling. Infect Immun 2009;77: 4574-83.

[23] Mahon RN, Sande OJ, Rojas RE, Levine AD, Harding CV, Boom WH. Mycobacterium tuberculosis ManLAM inhibits T-cell-receptor signaling by interference with ZAP-70, Lck and LAT phosphorylation. Cell Immunol 2012;275:98-105.

[24] Moreno C, Mehlert A, Lamb J. The inhibitory effects of mycobacterial lipoarabinomannan and polysaccharides upon polyclonal and monoclonal human T cell proliferation. Clin Exp Immunol 1988;74:206-10.

[25] Shabaana AK, Kulangara K, Semac I, Parel Y, Ilangumaran S, Dharmalingam K, Chizzolini C, Hoessli DC. Mycobacterial lipoarabinomannans modulate cytokine production in human T helper cells by interfering with raft/microdomain signalling. Cell Mol Life Sci 2005;62:179-87.

[26] Chatterjee D. The mycobacterial cell wall: structure, biosynthesis and sites of drug action. Curr Opin Chem Biol 1997;1:579-88.

[27] Jankute M, Grover S, Rana AK, Besra GS. Arabinogalactan and lipoarabinomannan biosynthesis: structure, biogenesis and their potential as drug targets. Future Microbiol 2012;7:129-47.

[28] Prinzis S, Chatterjee D, Brennan PJ. Structure and antigenicity of lipoarabinomannan from Mycobacterium bovis BCG. J General Microbiol 1993;139:2649-58.

[29] Khoo KH, Dell A, Morris HR, Brennan PJ, Chatterjee D. Inositol phosphate capping of the nonreducing termini of lipoarabinomannan from rapidly growing strains of Mycobacterium. J Biol Chem 1995;270:12380-9.

[30] Gilleron M, Himoudi N, Adam O, Constant P, Venisse A, Rivière M, Puzo G Mycobacterium smegmatis phosphoinositols-glyceroarabinomannans. Structure and localization of alkali-labile and alkali-stable phosphoinositides. J Biol Chem 1997;272:117-24.

[31] Bansal-Mutalik R, Nikaido H. Mycobacterial outer membrane is a lipid bilayer and the inner membrane is unusually rich in diacyl phosphatidylinositol dimannosides. Proc Natl Acad Sci U S A 2014;111:4958-63.

[32] Pitarque S, Larrouy-Maumus G, Payré B, Jackson M, Puzo G, Nigou J. The immunomodulatory lipoglycans, lipoarabinomannan and lipomannan, are exposed at the mycobacterial cell surface. Tuberculosis (Edinb) 2008;88: 560-5.

[33] Torrelles JB, Sieling PA, Arcos J, Knaup R, Bartling C, Rajaram MV, Stenger S, Modlin RL, Schlesinger LS. Structural differences in lipomannans from pathogenic and nonpathogenic mycobacteria that impact CD1b-restricted T cell responses. J Biol Chem 2011;286:35438-46.

[34] Chakraborty P, Kulkarni S, Rajan R, Sainis K. Drug resistant clinical isolates of Mycobacterium tuberculosis from different genotypes exhibit differential host responses in THP-1 cells. PLoS ONE 2013;8:e62966.

[35] Chen YY, Chang JR, Huang WF, Hsu SC, Kuo SC, Sun JR, Dou HY. The pattern of cytokine production in vitro induced by ancient and modern Beijing Mycobacterium tuberculosis strains. PLoS ONE 2014;9:e94296.

[36] Carmona J, Cruz A, Moreira-Teixeira L, Sousa C, Sousa J, Osorio NS, Saraiva AL Svenson S, Kallenius G, Pedrosa J, Rodrigues F, Castro AG, Saraiva M. Mycobacterium tuberculosis Strains are differentially recognized by TLRs with an impact on the immune response. PLoS ONE 2013;8:e67277.

[37] Sandegren L, Groenheit R, Koivula T, Ghebremichael S, Advani A, Castro E, Pennhag A, Hoffner S, Mazurek J, Pawlowski A, Kan B, Bruchfeld J, Melefors Ö, Källenius G. Genomic stability over 9 years of an isoniazid resistant Mycobacterium tuberculosis outbreak strain in Sweden. PLoS ONE 2011:6:e16647.

[38] Engele M, Stössel E, Castiglione K, Schwerdtner N, Wagner M, Bölcskei P, Röllinghoff M, Stenger S. Induction of TNF in human alveolar macrophages as a potential evasion mechanism of virulent Mycobacterium tuberculosis. J Immunol 2002;168:1328-37.

[39] Torrelles JB, Knaup R, Kolareth A, Slepushkina T, Kaufman TM, Kang P, Hill PJ, Brennan PJ, Chatterjee D, Belisle JT, Musser JM, Schlesinger LS. Identification of Mycobacterium tuberculosis clinical isolates with altered phagocytosis by human macrophages due to a truncated lipoarabinomannan. J Biol Chem 2008;283:31417-28. 
[40] Nigou J, Vercellone A, Puzo G. New structural insights into the molecular deciphering of mycobacterial lipoglycan binding to C-type lectins: lipoarabinomannan glycoform characterization and quantification by capillary electrophoresis at the subnanomole level. J Mol Biol 2000;299:1353-62.

[41] Gilleron M, Bala L, Brando T, Vercellone A, Puzo G. Mycobacterium tuberculosis H37Rv parietal and cellular lipoarabinomannans. Characterization of the acyland glyco-forms. J Biol Chem 2000;275:677-84.

[42] Khoo KH, Tang JB, Chatterjee D. Variation in mannose-capped terminal arabinan motifs of lipoarabinomannans from clinical isolates of Mycobacterium tuberculosis and Mycobacterium avium complex. J Biol Chem 2001;276: 3863-71.

[43] Doz E, Rose S, Nigou J, Gilleron M, Puzo G, Erard F, Ryffel B, Quesniaux VF. Acylation determines the toll-like receptor (TLR)-dependent positive versus TLR2-, mannose receptor-, and SIGNR1-independent negative regulation of pro-inflammatory cytokines by mycobacterial lipomannan. J Biol Chem 2007; 282:26014-25.

[44] Torrelles JB, Sieling PA, Zhang N, Keen MA, McNeil MR, Belisle JT, Modlin RL, Brennan PJ, Chatterjee D. Isolation of a distinct Mycobacterium tuberculosis mannose-capped lipoarabinomannan isoform responsible for recognition by CD1b-restricted T cells. Glycobiology 2012:22:1118-27.

[45] Schlesinger LS, Kaufman TM, Iyer S, Hull SR, Marchiando LK. Differences in mannose receptor-mediated uptake of lipoarabinomannan from virulent and attenuated strains of Mycobacterium tuberculosis by human macrophages. J Immunol 1996;157:4568-75.

[46] Beste DJ, Peters J, Hooper T, Avignone-Rossa C, Bushell ME, McFadden J. Compiling a molecular inventory for Mycobacterium bovis BCG at two growth rates: evidence for growth rate-mediated regulation of ribosome biosynthesis and lipid metabolism. J Bacteriol 2005;187:1677-84.

[47] Yang L, Sinha T, Carlson TK, Keiser TL, Torrelles JB, Schlesinger LS. Changes in the major cell envelope components of Mycobacterium tuberculosis during in vitro growth. Glycobiology 2013;23:926-34.

[48] Marshall BG, Wangoo A, Harrison LI, Young DB, Shaw RJ. Tumour necrosis factor-alpha production in human alveolar macrophages: modulation by inhaled corticosteroid. Eur Respir J Off J Eur Soc Clin Respir Physiol 2000;15: 764-70.

[49] Chatterjee D, Roberts AD, Lowell K, Brennan PJ, Orme IM. Structural basis of capacity of lipoarabinomannan to induce secretion of tumor necrosis factor. Infect Immun 1992;60:1249-53.

[50] Adams LB, Fukutomi Y, Krahenbuhl JL. Regulation of murine macrophage effector functions by lipoarabinomannan from mycobacterial strains with different degrees of virulence. Infect Immun 1993:61:4173-81.

[51] Bradbury MG, Moreno C. Effect of lipoarabinomannan and mycobacteria on tumour necrosis factor production by different populations of murine macrophages. Clin Exp Immunol 1993;94:57-63.

[52] Sibley LD, Hunter SW, Brennan PJ, Krahenbuhl JL. Mycobacterial lipoarabinomannan inhibits gamma interferon-mediated activation of macrophages. Infect Immun 1988;56:1232-6.

[53] Sibley LD, Adams LB, Krahenbuhl JL. Inhibition of interferon-gamma-mediated activation in mouse macrophages treated with lipoarabinomannan. Clin Exp Immunol 1990;80:141-8.

[54] Chan J, Fan XD, Hunter SW, Brennan PJ, Bloom BR. Lipoarabinomannan, a possible virulence factor involved in persistence of Mycobacterium tuberculosis within macrophages. Infect Immun 1991;59:1755-61.

[55] Brown MC, Taffet SM. Lipoarabinomannans derived from different strains of Mycobacterium tuberculosis differentially stimulate the activation of NF-kappa B and KBF1 in murine macrophages. Infect Immun 1995;63:1960-8.

[56] Miyoshi-Akiyama T, Matsumura K, Iwai H, Funatogawa K, Kirikae T. Complete annotated genome sequence of Mycobacterium tuberculosis Erdman. J Bacteriol 2012;194:2770.

[57] Roach TI, Barton CH, Chatterjee D, Blackwell JM. Macrophage activation: lipoarabinomannan from avirulent and virulent strains of Mycobacterium tuberculosis differentially induces the early genes c-fos, KC, JE, and tumor necrosis factor-alpha. J Immunol 1993;150:1886-96.

[58] Yoshida A, Koide Y. Arabinofuranosyl-terminated and mannosylated lipoarabinomannans from Mycobacterium tuberculosis induce different levels of interleukin-12 expression in murine macrophages. Infect Immun 1997;65: 1953-5.

[59] Dahl KE, Shiratsuchi H, Hamilton BD, Ellner JJ, Toossi Z. Selective induction of transforming growth factor beta in human monocytes by lipoarabinomannan of Mycobacterium tuberculosis. Infect Immun 1996;64:399-405.

[60] Afonso-Barroso A, Clark SO, Williams A, Rosa GT, Nóbrega C, Silva-Gomes S, Vale-Costa S, Ummels R, Stoker N, Movahedzadeh F, van der Ley P, Sloots A, Cot M, Appelmelk BJ, Puzo G, Nigou J, Geurtsen J, Appelberg R. Lipoarabinomannan mannose caps do not affect mycobacterial virulence or the induction of protective immunity in experimental animal models of infection and have minimal impact on in vitro inflammatory responses. Cell Microbiol 2013;15:660-74.

[61] Nigou J, Zelle-Rieser C, Gilleron M, Thurnher M, Puzo G. Mannosylated lipoarabinomannans inhibit IL-12 production by human dendritic cells: evidence for a negative signal delivered through the mannose receptor. J Immunol 2001;166:7477-85.

[62] Nigou J, Gilleron M, Cahuzac B, Bounéry JD, Herold M, Thurnher M, Puzo G. The phosphatidyl-myo-inositol anchor of the lipoarabinomannans from Mycobacterium bovis bacillus Calmette Guerin. Heterogeneity, structure, and role in the regulation of cytokine secretion. J Biol Chem 1997;272:23094-103.
[63] Geijtenbeek TB, Van Vliet SJ, Koppel EA, Sanchez-Hernandez M, Vandenbroucke-Grauls CM, Appelmelk B, Van Kooyk Y. Mycobacteria target DC-SIGN to suppress dendritic cell function. J Exp Med 2003;197:7-17.

[64] Dulphy N, Herrmann JL, Nigou J, Réa D, Boissel N, Puzo G, Charron D Lagrange PH, Toubert A. Intermediate maturation of Mycobacterium tuberculosis LAM-activated human dendritic cells. Cell Microbiol 2007;9:1412-25.

[65] Wu T, Guo S, Wang J, Li L, Xu L, Liu P, Ma S, Zhang J, Xu L, Luo Y. Interaction between mannosylated lipoarabinomannan and dendritic cell-specific intercellular adhesion molecule-3 grabbing nonintegrin influences dendritic cells maturation and T cell immunity. Cell Immunol 2011;272:94-101.

[66] Yonekawa A, Saijo S, Hoshino Y, Miyake Y, Ishikawa E, Suzukawa M, Inoue H, Tanaka M, Yoneyama M, Oh-Hora M, Akashi K, Yamasaki S. Dectin-2 is a direc receptor for mannose-capped lipoarabinomannan of mycobacteria. Immunity 2014; $41: 402-13$

[67] de Waal Malefyt R, Abrams J, Bennett B, Figdor CG, de Vries JE. Interleukin 10 (IL-10) inhibits cytokine synthesis by human monocytes: an autoregulatory role of IL-10 produced by monocytes. J Exp Med 1991;174:1209-20.

[68] Raetz CR. Biochemistry of endotoxins. Annu Rev Biochem 1990;59:129-70.

[69] Shimada M, Kadowaki T, Taniguchi Y, Inagawa H, Okazaki K, Soma G. The involvement of O-antigen polysaccharide in lipopolysaccharide in macrophage activation. Anticancer Res 2012;32:2337-41.

[70] Rossol M, Heine H, Meusch U, Quandt D, Klein C, Sweet MJ, Hauschildt S. LPS induced cytokine production in human monocytes and macrophages. Crit Rev Immunol 2011;31:379-446.

[71] Gringhuis SI, den Dunnen J, Litjens M, van der Vlist M, Geijtenbeek TB. Carbohydrate-specific signaling through the DC-SIGN signalosome tailors immunity to Mycobacterium tuberculosis, HIV-1 and Helicobacter pylori. Nat Immunol 2009;10:1081-8.

[72] Knutson KL, Hmama Z, Herrera-Velit P, Rochford R, Reiner NE. Lipoarabinomannan of Mycobacterium tuberculosis promotes protein tyrosine dephosphorylation and inhibition of mitogen-activated protein kinase in human mononuclear phagocytes. Role of the Src homology 2 containing tyrosine phosphatase 1. J Biol Chem 1998;273:645-52.

[73] Vignal C, Guérardel Y, Kremer L, Masson M, Legrand D, Mazurier J, Elass E. Lipomannans, but not lipoarabinomannans, purified from Mycobacterium chelonae and Mycobacterium kansasii induce TNF-alpha and IL-8 secretion by a CD14-toll-like receptor 2-dependent mechanism. J Immunol 2003;171: 2014-23.

[74] Nigou J, Vasselon T, Ray A, Constant P, Gilleron M, Besra GS, Sutcliffe I Tiraby G, Puzo G. Mannan chain length controls lipoglycans signaling via and binding to TLR2. J Immunol 2008:180:6696-702.

[75] Rajaram MV, Ni B, Morris JD, Brooks MN, Carlson TK, Bakthavachalu B Schoenberg DR, Torrelles JB, Schlesinger LS. Mycobacterium tuberculosis lipomannan blocks TNF biosynthesis by regulating macrophage MAPK-activated protein kinase 2 (MK2) and microRNA miR-125b. Proc Natl Acad Sci U S A 2011;108:17408-13.

[76] Doz E, Rose S, Court N, Front S, Vasseur V, Charron S, Gilleron M, Puzo G Fremaux I, Delneste Y, Erard F, Ryffel B, Martin OR, Quesniaux VF. Mycobacterial phosphatidylinositol mannosides negatively regulate host Toll-like receptor 4, MyD88-dependent proinflammatory cytokines, and TRIF-dependent co-stimulatory molecule expression. J Biol Chem 2009;284:23187-96.

[77] Takimoto H, Maruyama H, Shimada KI, Yakabe R, Yano I, Kumazawa Y. Interferon-gamma independent formation of pulmonary granuloma in mice by injections with trehalose dimycolate (cord factor), lipoarabinomannan and phosphatidylinositol mannosides isolated from Mycobacterium tuberculosis Clin Exp Immunol 2006;144:134-41.

[78] Guerin ME, Korduláková J, Alzari PM, Brennan PJ, Jackson M. Molecular basis of phosphatidyl-myo-inositol mannoside biosynthesis and regulation in mycobacteria. J Biol Chem 2010;285:33577-83.

[79] Court N, Rose S, Bourigault ML, Front S, Martin OR, Dowling JK, Kenny EF, O'Neill L, Erard F, Quesniaux VF. Mycobacterial PIMs inhibit host inflammatory responses through CD14-dependent and CD14-independent mechanisms. PLOS ONE 2011;6:e24631.

[80] Roach TI, Barton CH, Chatterjee D, Liew FY, Blackwell JM. Opposing effects of interferon-gamma on iNOS and interleukin-10 expression in lipopolysaccharide- and mycobacterial lipoarabinomannan-stimulated macrophages. Immunology 1995;85:106-13.

[81] Wang C, Yu X, Cao Q, Wang Y, Zheng G, Tan TK, Zhao H, Zhao Y, Wang Y, Harris DCh. Characterization of murine macrophages from bone marrow, spleen and peritoneum. BMC Immunol 2013;14:6.

[82] Gersuk GM, Razai LW, Marr KA. Methods of in vitro macrophage maturation confer variable inflammatory responses in association with altered expression of cell surface dectin-1. J Immunol Methods 2008;329:157-66.

[83] Jozefowski S, Sobota A, Pawłowski A, Kwiatkowska K. Mycobacterium tuberculosis lipoarabinomannan enhances LPS-induced TNF-alpha production and inhibits NO secretion by engaging scavenger receptors. Microb Pathog 2011;50:350-9.

[84] Hunter SW, Brennan PJ. Evidence for the presence of a phosphatidylinosito anchor on the lipoarabinomannan and lipomannan of Mycobacterium tuberculosis. J Biol Chem 1990;265:9272-9.

[85] Gagliardi MC, Lemassu A, Teloni R, Mariotti S, Sargentini V, Pardini M, Daffé M, Nisini R. Cell wall-associated alpha-glucan is instrumental for Mycobacterium tuberculosis to block CD1 molecule expression and disable the function of dendritic cell derived from infected monocyte. Cell Microbiol 2007;9: 2081-92. 
[86] Torrelles JB, Azad AK, Schlesinger LS. Fine discrimination in the recognition of individual species of phosphatidyl-myo-inositol mannosides from Mycobac terium tuberculosis by C-type lectin pattern recognition receptors. J Immunol 2006;177:1805-16.

[87] Kaur D, Angala SK, Wu SW, Khoo KH, Chatterjee D, Brennan PJ, Jackson M McNeil MR. A single arabinan chain is attached to the phosphatidylinositol mannosyl core of the major immunomodulatory mycobacterial cell envelope glycoconjugate, lipoarabinomannan. J Biol Chem 2014;289:30249-56.

[88] Hunter SW, Gaylord H, Brennan PJ. Structure and antigenicity of the phosphorylated lipopolysaccharide antigens from the leprosy and tubercle bacilli. J Biol Chem 1986;261:12345-51.

[89] Khoo KH, Dell A, Morris HR, Brennan PJ, Chatterjee D. Structural definition of acylated phosphatidylinositol mannosides from Mycobacterium tuberculosis: definition of a common anchor for lipomannan and lipoarabinomannan. Glycobiology 1995;5:117-27.

[90] Chatterjee D, Lowell K, Rivoire B, McNeil MR, Brennan PJ. Lipoarabinomannan of Mycobacterium tuberculosis. Capping with mannosyl residues in some strains. J Biol Chem 1992;267:6234-9.

[91] Chatterjee D, Hunter SW, McNeil M, Brennan PJ. Lipoarabinomannan. Multiglycosylated form of the mycobacterial mannosyl phosphatidylinositols. J Biol Chem 1992;267:6228-33.
[92] Chatterjee D, Bozic CM, McNeil M, Brennan PJ. Structural features of the arabinan component of the lipoarabinomannan of Mycobacterium tuberculosis. J Biol Chem 1991;266:9652-60.

[93] Rajaram MV, Brooks MN, Morris JD, Torrelles JB, Azad AK, Schlesinger LS, Mycobacterium tuberculosis activates human macrophage peroxisome proliferator-activated receptor gamma linking mannose receptor recognition to regulation of immune responses. J Immunol 2010;185:929-42.

[94] Pathak SK, Basu S, Bhattacharyya A, Pathak S, Kundu M, Basu J. Mycobacterium tuberculosis lipoarabinomannan-mediated IRAK-M induction negatively regulates Toll-like receptor-dependent interleukin-12 p40 production in macrophages. J Biol Chem 2005;280:42794-800.

[95] Blattes E, Vercellone A, Eutamène H, Turrin CO, Théodorou V, Majoral JP, Caminade AM, Prandi J, Nigou J, Puzo G. Mannodendrimers prevent acute lung inflammation by inhibiting neutrophil recruitment. Proc Natl Acad Sci U S A 2013;110:8795-800.

[96] Gilleron M, Nigou J, Nicolle D, Quesniaux V, Puzo G. The acylation state of mycobacterial lipomannans modulates innate immunity response through toll-like receptor 2. Chem Biol 2006;13:39-47. 